Article

\title{
Investigation of the Emission Characteristics of Light-Duty Diesel Vehicles in Korea Based on EURO-VI Standards According to Type of After-Treatment System
}

\author{
Hyung Jun Kim ${ }^{1}$, Sang Hyun Lee ${ }^{1}$, Sang Il Kwon ${ }^{1} \mathbb{1}$, Sangki Park ${ }^{1}{ }^{\mathbb{D}}$, Jonghak Lee ${ }^{1}$, \\ Ji Hoon Keel ${ }^{1,2}$, Jong Tae Lee ${ }^{1}$ and Suhan Park ${ }^{3, *(D)}$ \\ 1 National Institute of Environmental Research, 42 Hwangyeong-ro, Seo-gu, Inchon 22689, Korea; \\ junandjin@korea.kr (H.J.K.); Hyunny20000@korea.kr (S.H.L.); \\ heatksi@korea.kr (S.I.K.); psk3391@korea.kr (S.P.); jonghack2000@korea.kr (J.L.); episode23@korea.kr (J.H.K.); \\ leelee@korea.kr (J.T.L.) \\ 2 Department of Environmental Engineering, Inha University, 100 Inha-ro, Michuhol-gu, Incheon 22212, Korea \\ 3 School of Mechanical Engineering, Chonnam National University, 77 Yongbong-ro, Buk-gu, \\ Gwangju 61186, Korea \\ * Correspondence: suhanpark@jnu.ac.kr; Tel.: +82-62-530-1674
}

Received: 12 August 2020; Accepted: 17 September 2020; Published: 20 September 2020

check for updates

\begin{abstract}
This study analyzed the characteristics and distribution of emissions from diesel vehicles that are sold in Korea and satisfy the Euro-6 standards, according to after-treatment systems. To identify the emission distribution of diesel vehicles according to after-treatment systems, results of the certification tests conducted on 266 vehicle models were examined. Results of the certification tests on 86 vehicle models that were manufactured based on the standards for RDE after 2017 were examined according to the engine displacement and power. The emission characteristics of six vehicle models equipped with different types of after-treatment systems were verified through certification tests in the New European Driving Cycle and Worldwide Harmonized Light Vehicle Test Procedure modes and RDE tests, according to the after-treatment systems. Specifically, a chassis dynamometer and an emission analyzer were used in the certification test modes; a portable emissions measurement system was used in the RDE test. The results indicated that the amount of $\mathrm{NO}_{\mathrm{x}}$ emissions from diesel vehicles has been constantly decreasing since 2017 due to the implementation of standards for RDE and advancements in after-treatment systems. Furthermore, it was found that selective catalyst reduction systems must be installed in vehicles to satisfy Euro-6 standards for permissible emissions on real-roads.
\end{abstract}

Keywords: light-duty diesel vehicle; Euro-6; Emission New European Driving Cycle (NEDC); Worldwide Harmonized Light Vehicle Test Procedure (WLTP); Nitrogen oxides $\left(\mathrm{NO}_{\mathrm{x}}\right.$ ); Portable Emissions Measurement Systems (PEMS); green technologies

\section{Introduction}

The Ministry of Land, Infrastructure and Transport (MOLIT) has stated that 23.68 million vehicles have been registered in South Korea as of December 2019, and has projected this number to exceed 24 million by 2020 [1], which is approximately 2.2 times the number of vehicles in 1999, i.e., 11 million. The number of registered hybrid, electric, and hydrogen-powered fuel cell vehicles, which are classified as environmentally friendly vehicles, is increasing. However, this number is insignificant, because it accounts for only $1.7 \%$ of all registered vehicles. On the other hand, the number of diesel vehicles 
registered as of the end of 2019 was 9,957,543, which was approximately $42 \%$ of the total number of registered vehicles. In comparison, the number of diesel vehicles registered as of 2012 constituted $37 \%$ of the total number of registered vehicles. These data clearly show that the number of diesel vehicles has been constantly increasing.

Recently, environmental issues caused by the emissions of diesel vehicles have been emphasized. In 2015, the Volkswagen emissions scandal, also known as "Dieselgate", was revealed, and Volkswagen subsequently admitted to having manipulated two types of programs in the electric control units (ECUs) of certain models of its vehicles manufactured in accordance with the Euro 5 standards, to deceptively show that the exhaust gas recirculation (EGR) systems of these vehicles operated normally during vehicle emissions certification tests. However, the on-road performance of the EGR systems of these vehicles was substantially lower than that demonstrated in the emission tests, resulting in the emission of excessive amounts of pollutants. Following this, the European Union (EU) proposed tests and evaluation measures according to its guidelines on manipulation evaluation in January 2017, as well as evaluation standards for the operation of engine preheating, repetition of certification test modes, and Real Driving Emission (RDE) tests. Since then, the EU has been constantly strengthening the relevant standards, as shown in the Real Driving Emissions-Light-Duty Vehicles (RDE-LDV) evaluation measures, in which the conditions for cold start and the particulate number $(\mathrm{PN})$ were additionally applied [2]. Korea has adopted the Euro 6 standards for permissible emissions on light-duty diesel vehicles since September 2014. The Euro 6 standards for RDE were adopted in September 2017, and have since been applied to certified vehicles in Korea. The Worldwide Harmonized Light Vehicle Test Procedure (WLTP), a reinforced test mode in which the conditions of driving time and maximum speed increased compared to those of previous New European Driving Cycle (NEDC) certification test mode, has been implemented since October 2017 [3,4]. With the implementation of standards for PN, the standards for RDE have also been reinforced; for example, the previously permissible emission amount of $0.168 \mathrm{~g} / \mathrm{km}$ has been revised to $0.12 \mathrm{~g} / \mathrm{km}$ in 2020 .

Compliance tests for manipulation inspection are being conducted on certain vehicle models in accordance with the EU evaluation guidelines. Moreover, administrative actions against uncovered cases involving manipulation have been effected since 2015. In addition, it was alleged that some international vehicle manufacturers manipulated not only the EGR systems in their vehicles to conceal the status of decrease in the operating ratio of the EGR system under low temperature conditions, but also the control logic on the injection quantity of diesel exhaust fluid (DEF), which is used as a catalyst for the selective catalytic reduction (SCR) system. To handle these manipulation cases, compliance tests are being conducted on suspected cases involving the same vehicle models imported in Korea. As such, various systems for reducing $\mathrm{NO}_{x}$ emissions are being installed in diesel vehicles since the implementation of Euro 5 standards. Accordingly, the number of variables and factors associated with the ECUs used to control these systems has also been increasing. In particular, dosing control units (DCUs) of SCR systems are used to regulate the injection of DEF. Recently, certification tests in laboratories and the RDE standards implemented in October 2017 are being used to identify the status of satisfaction of standards for permissible emissions; additionally, relevant studies are being actively conducted [5-10].

Ko et al. [5] investigated the $\mathrm{NO}_{\mathrm{x}}$ emission characteristics of heavy-duty diesel vehicle under real-road driving conditions. They have demonstrated that the tightening of emissions regulations also has a significant effect on reducing vehicle emissions on real-roads. It was also reported that the measurement of emissions on the real-road requires a review of the test method (or procedure) taking into account the cold start conditions and engine power. O'Driscoll et al. [11] analyzed the results of real road tests conducted on 149 models of passenger cars to which the Euro 5 or Euro 6 standards were applied according to the fuel type. Based on their analysis, they reported that $\mathrm{NO}_{\mathrm{x}}$ emissions from passenger cars manufactured in accordance with the Euro 5 standards were higher by 3.5-4 times (in urban areas) than that of the passenger cars manufactured in accordance with the Euro 6 standards. They also stated that the $\mathrm{NO}_{x}$ emission from diesel cars was $86-96 \%$ less than that from 
gasoline cars. Huang et al. [12] compared the pollutants emitted by gasoline and diesel vehicles based on the portable emissions measurement system (PEMS). Mera et al. [13] examined the amount of $\mathrm{NO}_{\mathrm{x}}$ emitted from vehicles manufactured in compliance with the Euro 6 standards during real road driving, according to various $\mathrm{NO}_{x}$ reduction systems such as EGR, lean $\mathrm{NO}_{x}$ trap (LNT), and SCR. In particular, several studies [14-17] have been conducted through in-lab and real road driving tests to examine the properties of emissions generated from diesel vehicles that comply with the Euro 6 standards and have LNT systems installed in them. Myung et al. [16] published a research paper on the real-time $\mathrm{NO}_{x}$ reduction characteristics of Euro-6 diesel vehicles equipped with LNT in various vehicle emission certification cycles. They reported 1.5 to 6.6 times more $\mathrm{NO}_{\mathrm{x}}$ emissions in WLTC, FTP, and US06 cycle modes than in NEDC mode. The cause of this was attributed to frequent purges of LNT and high engine-out $\mathrm{NO}_{\mathrm{x}}$ emissions, according to the analysis. In particular, the DPF regeneration section in WLTC mode reported an increase of more than 8.8 times, indicating the need for optimization of the operation strategy and the after-treatment control strategy following DPF regeneration and frequent LNT purge of diesel vehicles under real-road driving conditions. Moreover, various domestic and international studies [18-20] have examined the amount of $\mathrm{CO}_{2}$ and $\mathrm{NO}_{\mathrm{x}}$ emissions generated from diesel vehicles that comply with the Euro 6 standards, during real road driving, through experiments and analysis of results.

Accordingly, the amount of emissions generated from vehicles in Korea that were manufactured in compliance with the Euro 6 standards and use various after-treatment systems should be analyzed through tests on certification modes and real road driving tests. In this study, the amount of $\mathrm{NO}_{\mathrm{x}}$ emissions generated from light-duty diesel vehicles that were manufactured after 2015 in accordance with the Euro 6 standards for permissible emissions was analyzed based on the results of certification tests, inspection for the certification of conformity, and occasional compliance tests conducted on the vehicles. An RDE test was conducted to evaluate the amount of $\mathrm{NO}_{\mathrm{x}}$ emissions generated from diesel vehicles equipped with PEMS. Moreover, the results of tests conducted on 266 vehicle models sold in Korea under the conditions of certification modes and those of RDE tests on 83 vehicle models were analyzed. Furthermore, the effects of displacement and power on various after-treatment systems were investigated. In addition, two vehicles for each after-treatment system were selected from among the vehicles certified based on the Euro 6 standards to analyze the effects of after-treatment systems on emissions through tests based on certification modes and RDE tests.

\section{Analysis of Certification Results, Experimental Set-Up, and Procedure}

\subsection{Analysis of Certification Results}

The Euro-6 standards for permissible emissions were first adopted for light-duty diesel vehicles in September 2014 in Korea. Consequently, the permitted level of $\mathrm{NO}_{x}$ emissions for diesel vehicles was reduced from $0.18 \mathrm{~g} / \mathrm{km}$ (Euro 5 standards) to $0.08 \mathrm{~g} / \mathrm{km}$. This study analyzed the amount of $\mathrm{NO}_{\mathrm{x}}$ emissions generated from 266 models of vehicles, which were certified to comply with the Euro 6 standards from 2015 and 2018, based on the results of the certification tests conducted on these vehicles. The vehicles were classified into two groups for analysis: 62 vehicle models that were produced and sold in Korea and 204 vehicle models that were imported and sold in Korea. Further, the RDE test results obtained by vehicle manufacturers are verified based on documents. To confirm the correspondence between the test and the practical results, the National Institute of Environmental Research (NIER) inspects the certification of conformity of certain vehicle models. Additionally, it conducts RDE tests to identify manipulation on certain vehicle models in occasional compliance tests. Considering this, the results obtained by NIER were also used in this study. The RDE tests for compliance, as well as inspection of certification of conformity, were conducted on 83 vehicle models. Specifically, 20 vehicle models were examined for compliance tests and 63 models for inspection for certification of conformity. The relevant details are listed in Table 1. 
Table 1. Number of car models considered in the analysis of emission characteristics.

\begin{tabular}{|c|c|c|c|c|c|c|c|}
\hline \multirow{2}{*}{$\begin{array}{l}\text { Vehicle Origin } \\
\text { Displacement }\end{array}$} & \multicolumn{3}{|c|}{ Domestic Vehicle } & \multicolumn{3}{|c|}{ Imported Vehicle } & \multirow[b]{2}{*}{ Total } \\
\hline & $\sim 1.6 \mathrm{~L}$ & $\begin{array}{c}1.6 \sim 2.5 \\
\mathrm{~L}\end{array}$ & $\sim 2.5 \mathrm{~L}$ & $\sim 1.6 \mathrm{~L}$ & $\begin{array}{c}1.6-2.5 \\
\text { L }\end{array}$ & $\sim 2.5 \mathrm{~L}$ & \\
\hline Certification test & 11 & 39 & 12 & 18 & 121 & 65 & 266 \\
\hline Compliance test & 9 & 20 & 2 & 6 & 15 & 11 & 63 \\
\hline $\begin{array}{l}\text { Real Driving Emission } \\
\text { (RDE) test }\end{array} \quad \begin{array}{c}\text { Certification of } \\
\text { Conformity }\end{array}$ & 6 & 6 & - & 1 & 5 & 2 & 20 \\
\hline Total of RDE test & 15 & 26 & 2 & 7 & 20 & 13 & 83 \\
\hline
\end{tabular}

Vehicles with a displacement of 1.6-2.5 L accounted for the highest proportion of all vehicles considered in the RDE tests, which includes 39 vehicle models manufactured in Korea and 121 imported vehicles. The number of imported and domestic car models with a displacement of $2.5 \mathrm{~L}$ or higher was found to be 65 and 12 , respectively.

To verify the emission characteristics of the 266 vehicle models that were certified and sold according to after-treatment systems, the status of application of after-treatment systems required to satisfy the Euro 6 standards for permissible $\mathrm{NO}_{\mathrm{x}}$ emissions was confirmed based on the documents submitted for the application of certification. It is known that LNT and SCR systems are mainly used for reducing $\mathrm{NO}_{\mathrm{x}}$ emissions. In recent years, both these systems are simultaneously installed to satisfy the standards for RDEs. It was found that both the LNT and SCR systems were applied in 31 domestic vehicle models. On the other hand, imported vehicle models mainly had only SCR systems, and the number of imported vehicle models equipped with both LNT and SCR systems was 28 . The EGR or LNT system was applied in vehicle models that were manufactured in compliance with the Euro 6 standards between 2014 and 2015. The details of the status of after-treatment systems installed in vehicle models are listed in Table 2.

Table 2. Types of after-treatment system in certification vehicles. EGR-exhaust gas recirculation, LNT_lean $\mathrm{NO}_{x}$ trap, SCR—selective catalytic reduction.

\begin{tabular}{cccccccccc}
\hline Vehicle Origin & \multicolumn{4}{c}{ Domestic Vehicle } & \multicolumn{3}{c}{ Imported Vehicle } & \multirow{2}{*}{ Total } \\
\cline { 1 - 9 } After-Treatment System & EGR & LNT & SCR & LNT+SCR & EGR & LNT & SCR & LNT+SCR & \\
\hline Number of cars & - & 22 & 9 & 31 & 15 & 44 & 117 & 28 & 266 \\
\hline
\end{tabular}

\subsection{Experimental Set-Up and Procedure}

\subsubsection{Test Vehicles}

In this study, diesel vehicles that comply with the Euro 6 standards were selected, and experiments were conducted on them to identify the effects of various after-treatment systems (such as LNT, SCR, and the combination of LNT and SCR). To compare the test vehicles based on the after-treatment systems equipped with them, only vehicles with a displacement of $\sim 2 \mathrm{~L}$ (1900 to $2200 \mathrm{cc}$ ) were selected. Table 3 lists the particulars of the test vehicles.

Table 3. Specifications of test vehicles.

\begin{tabular}{cccc}
\hline Test Vehicle & Max Power (ps) & Displacement (cc) & After-Treatment System \\
\hline Veh. 1 & 150 & 1997 & EGR + LNT \\
Veh. 2 & 170 & 1956 & EGR + LNT \\
Veh. 3 & 170 & 2143 & EGR + SCR \\
Veh. 4 & 150 & 1968 & EGR + SCR \\
Veh. 5 & 190 & 1995 & EGR + LNT + SCR \\
Veh. 6 & 186 & 1995 & EGR + LNT + SCR \\
\hline
\end{tabular}




\subsubsection{Experimental Setup}

Experimental Apparatus (Chassis Dynamometer and Emission Analyzer)

As shown in Figure 1, a vehicle emission measurement equipment consists of a chassis dynamometer, emission analyzer, constant volume sampler (CVS), particulate matter (PM) measurement device, and PN counter for indoor tests. The chassis dynamometer was used to reproduce the patterns and level of drag observed during real road driving tests in laboratories. Through a coast-down test in which the drag coefficients and test weight according to the vehicle model were input to represent the data of drag and conditions of real roads, the chassis dynamometer similarly reproduces the amount of emissions generated during real road driving based on rolling resistance, gradient, and wind resistance from the surface. The detailed specifications of the dynamometer are listed in Table 4.

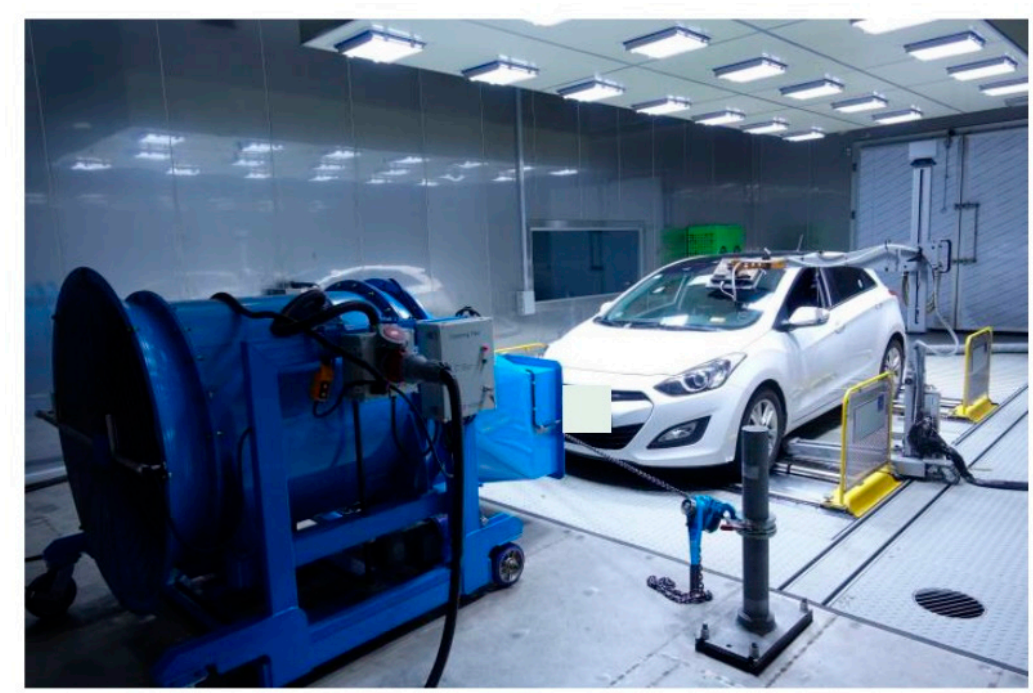

(a)

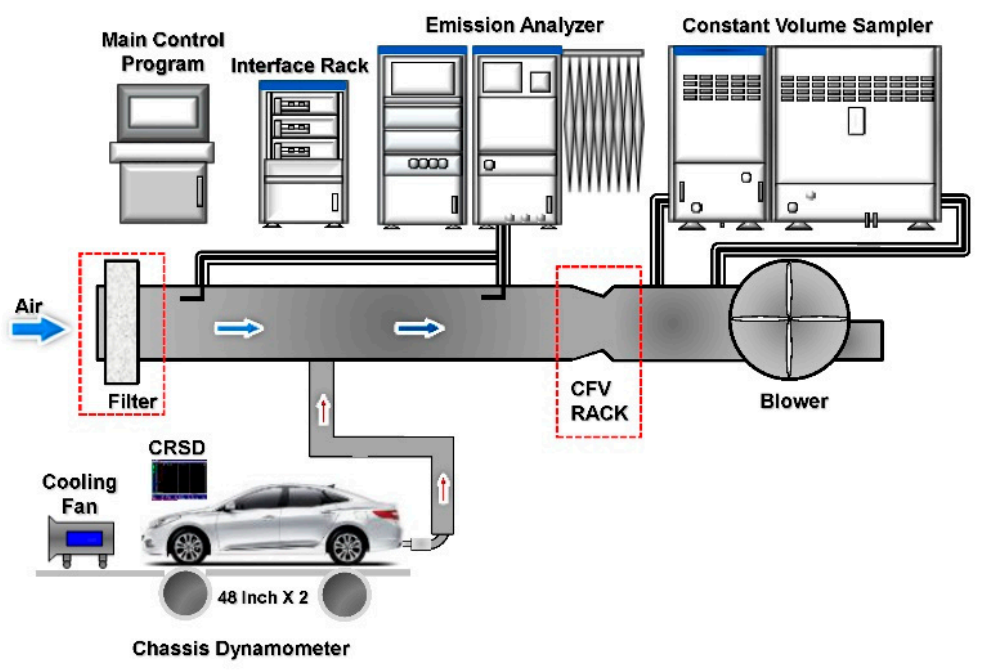

(b)

Figure 1. Experimental apparatus: (a) Picture of emission test system using chassis dynamometer and (b) its schematic. 
Table 4. Specifications of test dynamometer.

\begin{tabular}{cc}
\hline Item & Specification \\
\hline Power Absorption & AC motor $(150 \mathrm{~kW})$ \\
Roller & 48 “INLINE $4 \times 2$ \\
Vmax Dyno & $200 \mathrm{~km} / \mathrm{h}$ \\
Min Inertia & $800 \mathrm{~kg}$ \\
Max Inertia & $5448 \mathrm{~kg}$ \\
Maximum calibration force & $10,200 \mathrm{~N}$ \\
Fan & Vehicle proportional type \\
\hline
\end{tabular}

The emission analyzer examines the emissions generated from vehicles through sampling using the CVS, and can be used to investigate $\mathrm{CO}, \mathrm{CO}_{2}, \mathrm{NO}_{\mathrm{x}}$, and $\mathrm{HC}$ emissions. Analytic methods vary according to the type of gas being analyzed. The $\mathrm{HC}$ emissions were analyzed using a heated flame ionization detector (HFID) based on the principle that the electrical conductivity of a gas is directly proportional to the concentration of charged particles in it. Further, $\mathrm{CO}$ and $\mathrm{CO}_{2}$ were analyzed based on the principle that non-dispersive infrared (NDIR) gaseous matter exhibits certain absorption spectra depending on infrared light, which is used to calculate the concentration of a specific component. The $\mathrm{NO}_{\mathrm{x}}$ emission was analyzed via chemi-luminescent detection (CLD). Chemiluminescence is a chemical reaction generated by the emission of visible light. Activated $\mathrm{NO}_{2}$ is formed when $\mathrm{NO}$ is oxidized in the presence of ozone and low pressure; subsequently, activated molecules return to the ground state and emit light due to chemiluminescence. Because ozone is maintained in excess amounts in a furnace, the concentration of NO in a sample is determined by the amount of emitted light. The detailed specifications of the gas analyzer are listed in Table 5. Figure 2 shows the pictures of each experimental devices.

Table 5. Specifications of the test gas analyzer.

\begin{tabular}{|c|c|c|c|c|}
\hline Item & \multicolumn{4}{|c|}{ Specification } \\
\hline Component & $\mathrm{CO}$ & $\mathrm{CO}_{2}$ & $\mathrm{HC}$ & $\mathrm{NO}_{\mathrm{x}}$ \\
\hline Measuring principle & NDIR & NDIR & HFID & CLD \\
\hline $\begin{array}{l}\text { Measuring concentration } \\
\text { range }\end{array}$ & $50,100,200,1000 \mathrm{ppm}$ & $1,2,3,6 \%$ & $10,20,50,200 \mathrm{ppm}$ & $10,20,50,1000 \mathrm{ppm}$ \\
\hline Repeatability & \multirow{3}{*}{\multicolumn{4}{|c|}{$\begin{array}{l}\text { With } \pm 1 \% \text { of fuel scale per } 8 \mathrm{~h} \\
\text { (at an ambient temperature difference of } 5{ }^{\circ} \mathrm{C} \text { ) } \\
\text { With } \pm 1 \% \text { of fuel scale per } 8 \mathrm{~h} \\
\text { (at an ambient temperature difference of } 5{ }^{\circ} \mathrm{C} \text { ) } \\
\text { With } \pm 1 \% \text { of fuel scale per } 8 \mathrm{~h} \\
\text { (at an ambient temperature difference of } 5{ }^{\circ} \mathrm{C} \text { ) }\end{array}$}} \\
\hline Zero drift & & & & \\
\hline Span drift & & & & \\
\hline
\end{tabular}

The CVS dilutes the emissions generated from a test vehicle driven on the roller of the chassis dynamometer by using a certain amount of air in an exhaust pipe, and collects them in a sample collection bag. The PM measuring device has sufficient flow, and a heat exchanger is used to maintain the temperature of the diluted sample gas at $52{ }^{\circ} \mathrm{C}$ during the collection of PM sample. The particle collection system of the PN measuring device comprises dilution tunnels, a particle collection probe, volatile particle reduction device located at the entrance, and a particle transfer tube. The point of particle collection is located between the dilution tunnels. 


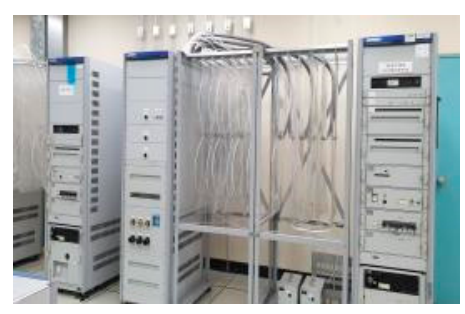

(a)

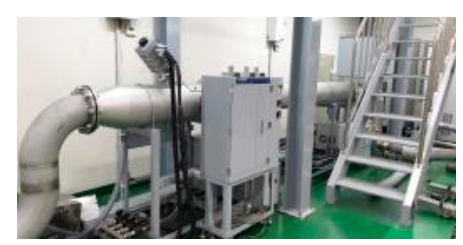

(b)

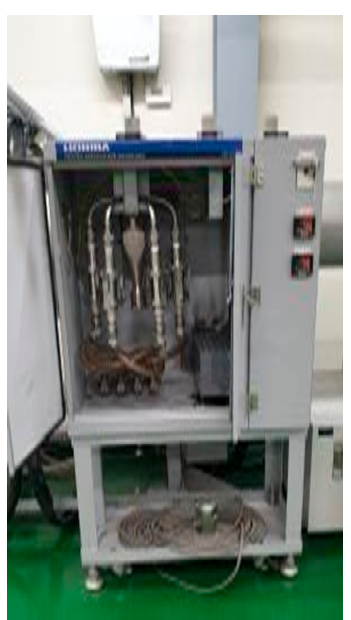

(c)

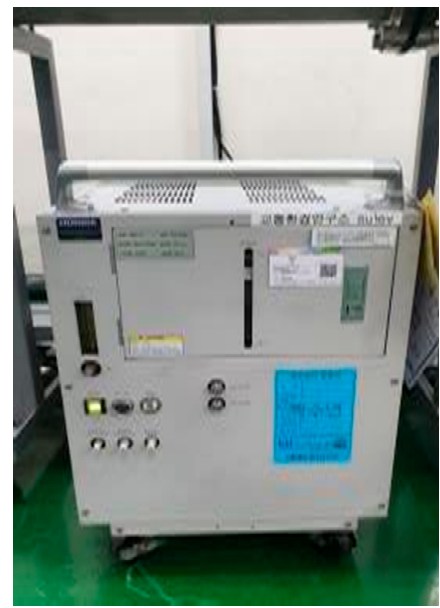

(d)

Figure 2. Experimental apparatus-Emission analyzer. (a) Exhaust gas analyzer; (b) Constant volume sampler (CVS) tunnel; (b) Constant volume sampler (CVS) tunnel; (d) Particle number measuring device.

Experimental Apparatus (PEMS)

The PEMS was used to conduct the RDE-LDV test. To measure the amount of emissions generated during real road driving, the PEMS consists of an exhaust gas concentration analyzer, exhaust gas flow measuring device, global positioning system (GPS) for measuring the location, altitude, and speed of vehicle, sensors for measuring the atmospheric temperature, relative humidity, atmospheric pressure, and vehicle speed, and a power supply unit. Specifically, the PEMS for light-duty vehicles, which was developed by Sensors, Inc. (USA), was used to conduct the RDE-LDV test in this study. Table 6 lists the specifications of the PEMS used in this study.

Table 6. Specifications of portable emissions measurement system (PEMS) used in this study.

\begin{tabular}{ccc}
\hline Item & Principle & Range \\
\hline $\mathrm{CO}$ & Heated non-dispersive infrared & $0-8 \mathrm{vol} \%$ \\
$\mathrm{CO}_{2}$ & (NDIR) & $0-18 \mathrm{vol} \%$ \\
$\mathrm{NO}, \mathrm{NO}_{\mathrm{x}}$ & Heated NDIR & $0-3000 \mathrm{ppm}$ \\
Exhaust flow & NDUV & $0-670 \mathrm{~kg} / \mathrm{h}$ \\
Standard signal measurement & Pilot flow meter & Ambient pressure, temperature, humidity \\
& Exhaust temperature and pressure, global positioning system (GPS) \\
\hline
\end{tabular}

\subsubsection{Experimental Procedure}

\section{Test Mode (Chassis Dynamometer)}

The tests on diesel vehicles were conducted in the certification test mode and real road driving test mode. As for indoor tests, the modes of NEDC and WLTC were used, which are certification test modes for diesel vehicles. As shown in Figure 3, the NEDC driving mode consists of an urban driving mode (Part 1), including four basic urban driving modes and an additional urban driving mode (Part 2) [3]. 


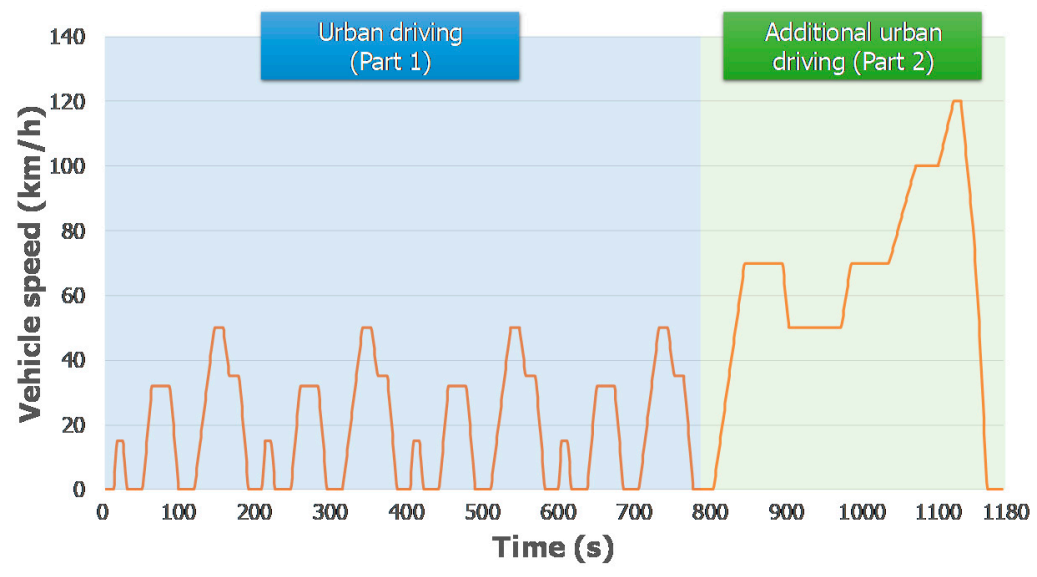

Figure 3. New European Driving Cycle (NEDC) test cycle.

Figure 4 shows the vehicle speed profile for the time. The WLTC mode was developed by the World Forum for Harmonization of Vehicle Regulations (WP.29) in the United Nations Economic Commission for Europe (UNECE) based on the driving data obtained from different countries to overcome the problems with the NEDC mode, which failed to sufficiently reflect the real road driving characteristics. The characteristics of the WLTC mode, which are different from those of the NEDC mode, include longer driving distance, less idle time, and a higher frequency of occurrence of acceleration and deceleration, which are found during real road driving. The WLTC test cycles are classified according to the maximum speed of the test vehicle and its rated power (PMR) relative to its curb mass, including the weight of a driver equivalent to $75 \mathrm{~kg}$. A comparison of the NEDC and WLTC test modes is presented in Table 7.

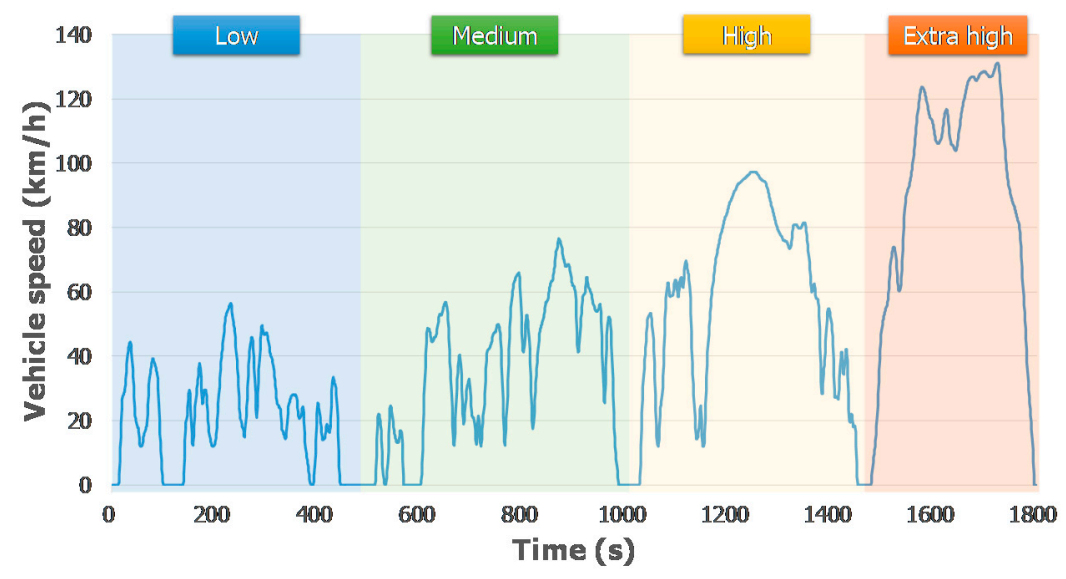

Figure 4. WLTC class vehicle speed profile [4].

Table 7. Comparison of NEDC and WLTC test modes.

\begin{tabular}{ccc}
\hline Test Mode & NEDC & WLTC \\
\hline Driving time & $1180 \mathrm{~s}$ & $1800 \mathrm{~s}$ \\
\hline Driving distance & $11 \mathrm{~km}$ & $23.26 \mathrm{~km}$ \\
\hline Maximum speed & $120 \mathrm{~km} / \mathrm{h}$ & $131.3 \mathrm{~km} / \mathrm{h}$ \\
\hline Average speed & $33.6 \mathrm{~km} / \mathrm{h}$ & $46.5 \mathrm{~km} / \mathrm{h}$ \\
\hline
\end{tabular}


Test Method (RDE)

The RDE test should be conducted in consideration of general driving patterns, driving conditions, and intake weight. Moreover, appropriate test routes for the driving conditions of urban areas, rural areas, and motorways should be selected. Road types are determined based on a topographic map. Regarding urban driving, roads supporting a maximum speed of $60 \mathrm{~km} / \mathrm{h}$ or lower should be selected. Although the maximum speed exceeds $60 \mathrm{~km} / \mathrm{h}$ in certain sections, it should be maintained at $60 \mathrm{~km} / \mathrm{h}$ or lower in the RDE tests. If the performance of a test vehicle and the amount of emissions generated from it are affected in the process of data collection by the ECU, the vehicle is determined to have been manipulated and considered inappropriate. The RDE tests should be conducted under both cold- and hot-start conditions.

The duration of a cold-start RDE test is $5 \mathrm{~min}$ after the initial operation of an engine. The measurement of cold-start driving is terminated when the temperature of the coolant reaches $70{ }^{\circ} \mathrm{C}$. Moreover, the mean vehicle speed should be maintained between $15-40 \mathrm{~km} / \mathrm{h}$, and the maximum speed should be limited to $60 \mathrm{~km} / \mathrm{h}$ or lower. The routes for cold start driving include an urban route of $\sim 28 \mathrm{~km}$ from the NIER to the Pyeongri field, a rural route of $\sim 32 \mathrm{~km}$ from the Pyeongri field to the Sinpyeong interchange (IC), and a motorway route from the Gangmae IC to the Geumsan IC (Figure 5).

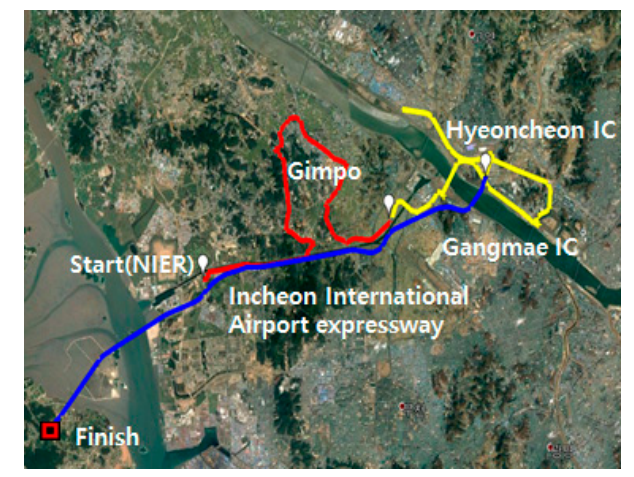

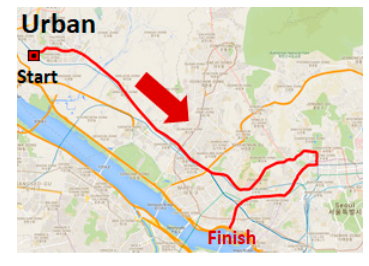

Urban

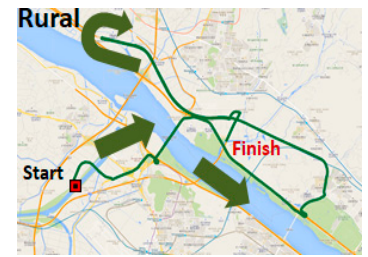

Rural

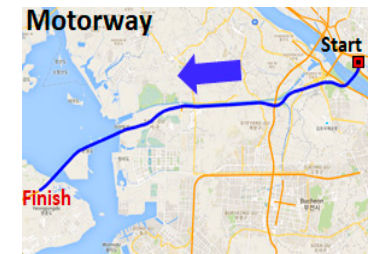

Motorway

Figure 5. Driving routes for the Real Driving Emissions-Light-Duty Vehicles (RDE-LDV) cold-start test.

The routes for hot-start driving include an urban route of $\sim 23 \mathrm{~km}$ from the Neunggok crossroad to the Seogang Bridge, a rural route of $\sim 21 \mathrm{~km}$ from the Seogang Bridge to the Gangmae IC, and a motorway route of $\sim 30 \mathrm{~km}$ from the Gangmae IC to the Geumsan IC. The satellite images of the test routes are shown in Figure 6.

The driving route conditions for the RDE tests are as follows. First, driving was performed on the routes in the order of urban, rural, and motorway routes. The proportion of driving performed on urban, rural, and motorway routes was approximately $34 \%, 33 \%$, and $33 \%$, respectively. The allowable error was set as $\pm 10 \%$, and the proportion of driving on the urban route was maintained to account for $29 \%$ or higher. The minimum driving distance for each route was set as $16 \mathrm{~km}$ and driving time was set as $90-120 \mathrm{~min}$. A summary of cold- and hot-start conditions for RDE is presented in Table 8. 


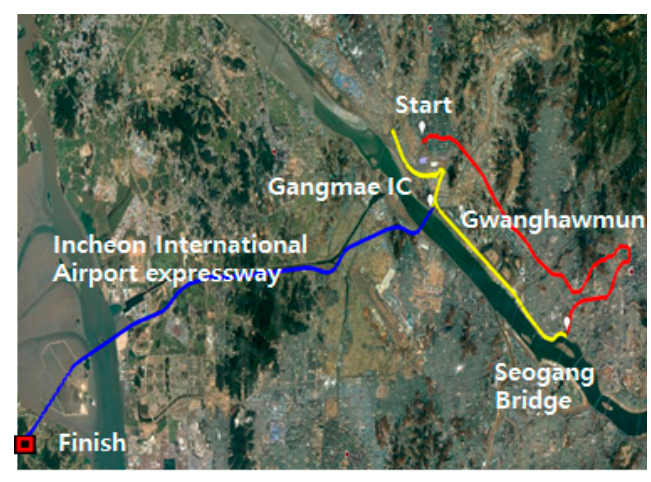

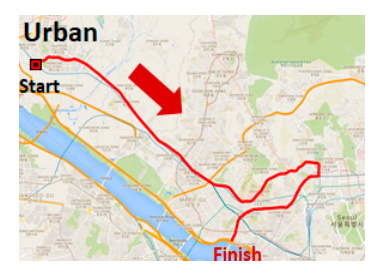

Urban

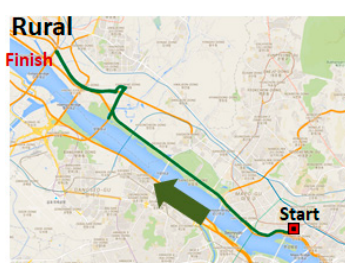

Rural

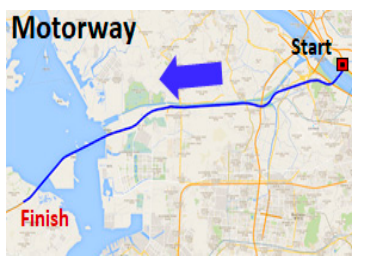

Motorway

Figure 6. Driving routes for the RDE-LDV hot-start test.

Table 8. Revised road test routes for representativeness.

\begin{tabular}{|c|c|c|c|}
\hline Route & Link & Road Type & Distance $(\mathrm{km}$ \\
\hline \multirow{3}{*}{$\begin{array}{l}\text { Cold start } \\
\text { condition }\end{array}$} & NIER-(Gimpo) Bukbyeon Crossroad-Pyeongri Field & Urban & 28 \\
\hline & $\begin{array}{l}\text { Pyeongri Field-Gaehwa IC-Hyeoncheon } \\
\text { IC-Sinpyeong IC } \\
\end{array}$ & Rural & 32 \\
\hline & (Incheon Airport) Gangmae IC-Geumsan IC & Motorway & 30 \\
\hline \multirow{3}{*}{ Hot start condition } & $\begin{array}{l}\text { (Ilsan) Neunggok Crossroad-Gwanghawmun } \\
\text { Three-way Intersection-Seogang Bridge }\end{array}$ & Urban & 23 \\
\hline & $\begin{array}{c}\text { Seogang Bridge-Gangmae IC-Neunggok } \\
\text { IC-Gangmae IC }\end{array}$ & Rural & 21 \\
\hline & (Incheon Airport) Gangmae IC-Geumsan IC & Motorway & 30 \\
\hline
\end{tabular}

\section{Results and Discussion}

\subsection{Analysis of $\mathrm{NO}_{x}$ Emission from Certification Results in Korea}

\subsection{1. $\mathrm{NO}_{\mathrm{x}}$ Emission According to the Year of Certification}

The standards for permissible levels of emissions from light-duty diesel vehicles were adopted in 2014 in Korea, and diesel vehicles certified to satisfy the Euro 6 standards are being sold since September 2014. In this study, the characteristics of $\mathrm{NO}_{\mathrm{x}}$ emissions, which were generated from diesel vehicles certified to comply with the Euro 6 standards, were examined based on the results of the certification tests performed on 266 vehicle models. Among the vehicle models, 62 vehicle models were certified by Korean vehicle manufacturers, accounting for $23 \%$ of the entire vehicle models certified. A total of 204 vehicle models were certified by foreign vehicle manufacturers before being imported to Korea. The number of imported vehicle models accounted for $77 \%$ of all certified vehicles, approximately three times the number of vehicle models certified by Korean vehicle manufacturers. The test results on $\mathrm{NO}_{\mathrm{x}}$ emissions, which were obtained in certification test modes and submitted by the vehicle manufacturers for verification of certification, were analyzed in this study. Figure 7 presents the plots representing a change in the distribution of $\mathrm{NO}_{x}$ emissions according to the year of certification. The result of the distribution of $\mathrm{NO}_{\mathrm{x}}$ emissions according to the certification year indicates that the amount of $\mathrm{NO}_{\mathrm{x}}$ 
emissions was lower than that permissible by the Euro 6 standards (i.e., $0.08 \mathrm{~g} / \mathrm{km}$ ), and that it was mostly between $0.04-0.07 \mathrm{~g} / \mathrm{km}$ from 2014 to 2016. Lower $\mathrm{NO}_{\mathrm{x}}$ emissions were increasingly observed in the distribution after 2017, which indicates that the amount of $\mathrm{NO}_{x}$ emissions constantly decreased due to the implementation of standards for RDE and the advancements in after-treatment systems. Moreover, the amount of $\mathrm{NO}_{\mathrm{x}}$ emissions in 2018 was measured in the WLTP mode. Although a direct comparison is difficult, it is estimated that the amount of $\mathrm{NO}_{\mathrm{x}}$ emissions obtained in the WLTP mode is less than that obtained in the existing NEDC mode, because the conditions of the former mode were strengthened with the application of increased driving distance and maximum speed.

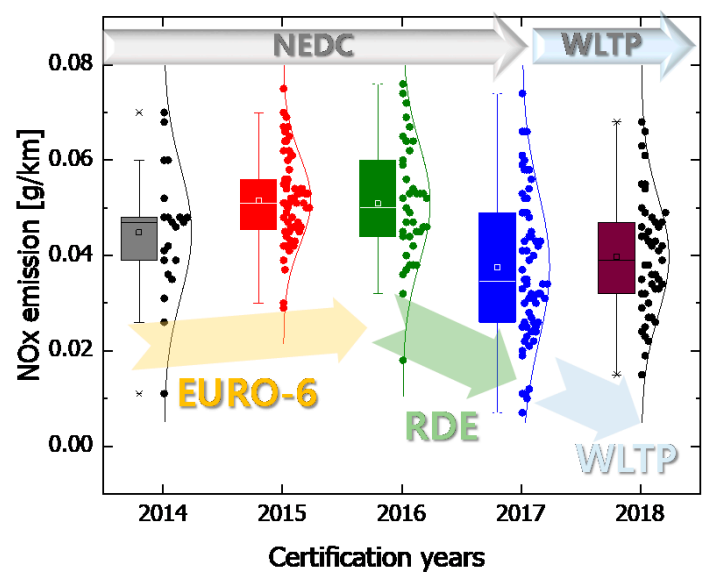

Figure 7. $\mathrm{NO}_{\mathrm{x}}$ emissions distribution according to certification year (test mode) in light-duty diesel vehicles.

\subsection{2. $\mathrm{NO}_{\mathrm{x}}$ Emission According to Vehicle Power and Displacement}

The amount of $\mathrm{NO}_{\mathrm{x}}$ emissions generated from 62 domestic vehicle models and 204 imported vehicle models, which were obtained through certification tests, were analyzed. In addition, the details of after-treatment systems for reducing $\mathrm{NO}_{x}$ emissions, which were reported in the documents related to certification, were examined according to the vehicle models. Further, the characteristics of emissions by after-treatment systems of domestic and imported vehicle models according to power and displacement were examined (Figures 8 and 9). Figure 8 shows the characteristics of emissions according to power, and Figure 10 shows those according to displacement. As shown in Figure 8, the range of power of domestic vehicle models was 100-250 ps. Contrarily, imported vehicle models had a broader range of power, i.e., $90-400$ ps. It was also found that the number of Korean vehicle manufacturers was five and the number of foreign vehicle manufacturers whose vehicle models were imported to Korea was 15 or higher. From this result, it can be inferred that a large number of vehicles manufactured with high power in other countries had been imported to Korea to satisfy the requirements of consumers. The results of this analysis indicate that the LNT system was installed in both domestic and imported vehicle models having a power of 100-250 ps, and the SCR system was installed in vehicle models having a power of 200 ps or higher. A combination of LNT and SCR systems, which satisfies the standards for RDE, was widely applied in vehicle models having a power of 150 ps or higher. It was also confirmed that the amount of $\mathrm{NO}_{\mathrm{x}}$ emissions generated from imported vehicle models tends to be low. 


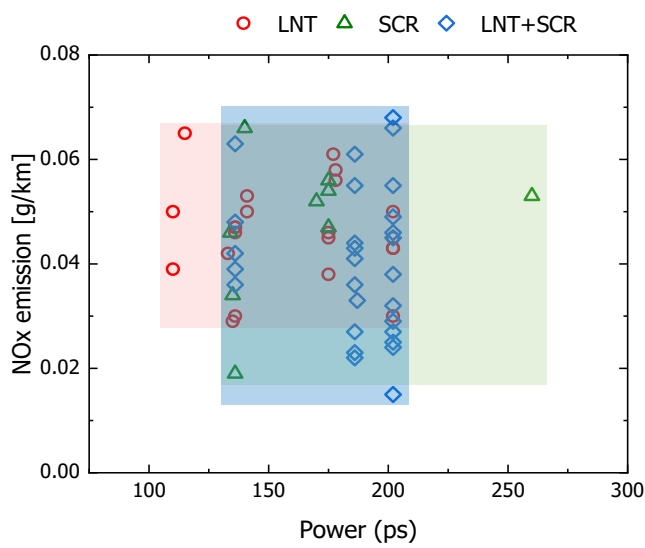

(a)

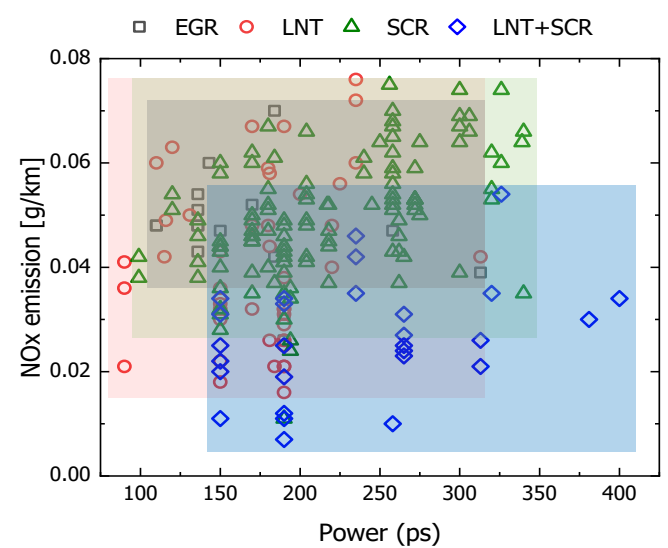

(b)

Figure 8. $\mathrm{NO}_{\mathrm{x}}$ emission characteristics according to after-treatment system and power for the domestic and imported vehicles in Korea. (a) Domestic vehicles; (b) Imported vehicles.

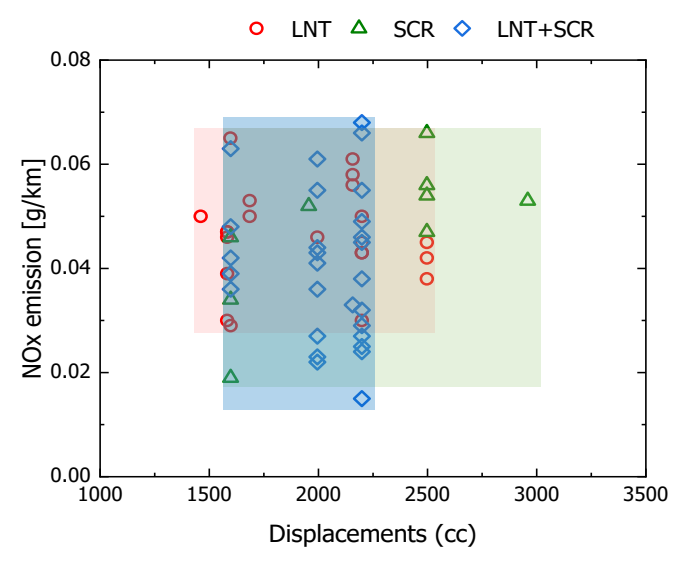

(a)

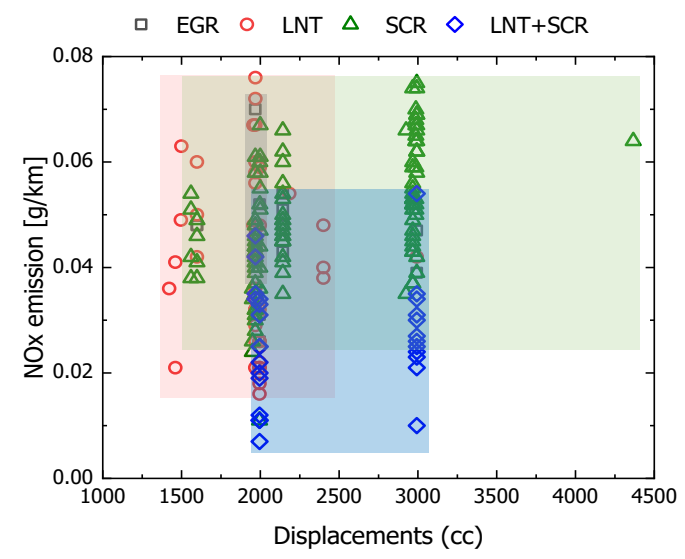

(b)

Figure 9. $\mathrm{NO}_{\mathrm{x}}$ emission characteristics according to after-treatment system and vehicle displacement for the domestic and imported vehicles in Korea. (a) Domestic vehicles; (b) Imported vehicles.

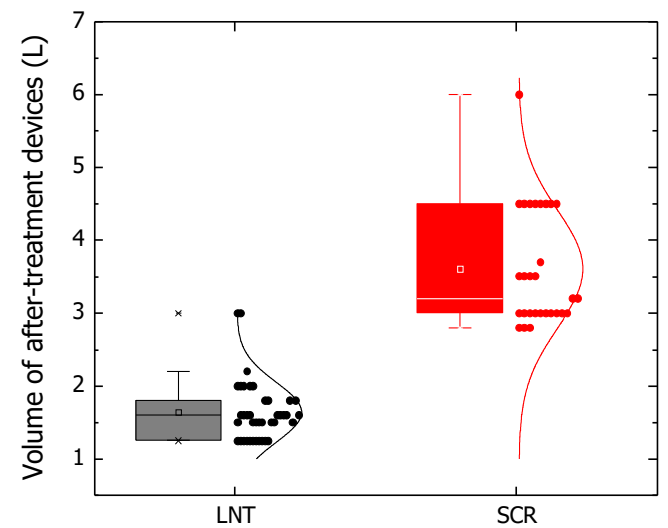

(a)

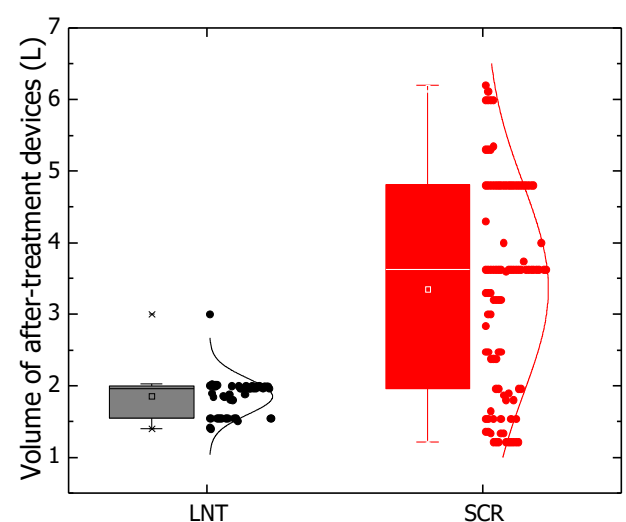

(b)

Figure 10. Volume distribution of after-treatment devices (LNT and SCR) in domestic and imported Euro-6 vehicles in Korea. (a) Domestic vehicles; (b) Imported vehicles.

Figure 9 shows the amount of $\mathrm{NO}_{\mathrm{x}}$ emissions by after-treatment systems according to displacement. All vehicle models, except one imported vehicle model, had a displacement of 1.5-3.0 L. As indicated by 
this result, diesel vehicles are unlikely to be manufactured with high displacement because the power relative to displacement of diesel vehicles is greater than that of gasoline vehicles. The application of EGR or LNT systems was limited to domestic and imported vehicle models with a displacement of 2500 cc or less. The SCR system was found to be widely installed in all vehicle models regardless of the displacement. This result indicates that a combination of LNT and SCR systems was applied in vehicle models regardless of power and displacement, and the amount of $\mathrm{NO}_{\mathrm{x}}$ emissions generated through such a combination was low. Based on these results, it can be concluded that the LNT system is appropriate for vehicle models with low power and displacement for reducing $\mathrm{NO}_{\mathrm{x}}$ emissions, and the SCR system is applicable to all vehicle models regardless of displacement. Furthermore, it is verified that the combination of LNT and SCR systems is more effective than the other systems.

\subsection{3. $\mathrm{NO}_{\mathrm{x}}$ After-Treatment Systems}

An analysis of the after-treatment systems installed in 266 vehicle models sold in Korea indicated that the SCR system was installed in 126 vehicle models, accounting for $\sim 47 \%$ of all vehicle models. Since the implementation of the standards for RDE in 2017, the number of vehicle models equipped with the combination of LNT and SCR systems was found to be increasing - both the LNT and SCR systems were simultaneously applied in 59 vehicle models. The LNT system was installed in 26 vehicle models; however, it is estimated that the number of vehicles with the LNT system will decrease rapidly. The capacity of the LNT system applied in both domestic and imported vehicle models was 1-2 L, because most vehicle models with the LNT system had a low displacement of 1.5-2 L and a similar capacity of the emission deduction system (Figure 10). However, the capacity of the SCR system installed in domestic vehicle models was 3-5 L. On the other hand, the capacity of the SCR system applied in imported vehicle models was greater, being 1-6 L. It is inferred that the capacity of SCR systems installed in domestic and imported vehicle models varies because the power and displacement vary with every vehicle model and the type of SCR control logic differs with each vehicle manufacturer.

\subsection{4. $\mathrm{NO}_{\mathrm{x}}$ Emission Characteristics of RDE Test Results}

The standards for RDE for light-duty diesel vehicles have been adopted since September 2017 in Korea. The currently permissible standard for $\mathrm{NO}_{\mathrm{x}}$ emissions is $0.168 \mathrm{~g} / \mathrm{km}$, which is 2.1 times lower than that in certification tests, and is expected to decrease to $0.12 \mathrm{~g} / \mathrm{km}$ after 2020. Moreover, the SCR coated diesel particulate filter (SDPF) system, a complex device in which an SCR catalyst is coated on the PM filter, is also being used to solve the spatial problem caused in the application process of the SCR system. Since October 2017, it has been required to satisfy both standards for permissible emissions and emission regulations on real roads in the WLTP mode during certification tests. In this study, the results of measurement of RDE generated from 83 vehicle models that were certified to comply with the Euro 6 standards through certification of conformity and compliance tests were examined for each after-treatment system. Figure 11 shows the results of the RDE measured according to power and displacement. These results indicate that the vehicle models equipped with the LNT system produced $\mathrm{NO}_{\mathrm{x}}$ emissions of $0.03-1.67 \mathrm{~g} / \mathrm{km}$ during real road driving. This indicates that the amount of $\mathrm{NO}_{x}$ emissions was as great as the deviation of the amount of $\mathrm{NO}_{x}$ emissions according to vehicle models. This result was obtained because some vehicle models equipped with the LNT system did not comply with the standards for RDE. Moreover, the limited reduction capacity of the LNT system also affected the test results. The thus obtained result of great deviation indicates that the amount of $\mathrm{NO}_{\mathrm{x}}$ emissions observed in the certification tests is significantly different from that observed during real road driving. Moreover, it was determined that vehicle models equipped with the SCR system generated $\mathrm{NO}_{\mathrm{x}}$ emissions of $0.003-0.711 \mathrm{~g} / \mathrm{km}$. Thus, these vehicle models generate lower $\mathrm{NO}_{\mathrm{x}}$ emissions than those equipped with the LNT system. In addition, the combination of LNT and SCR (SDPF) systems was found to be applied in the vehicle models manufactured in compliance with the standards for the WLTP mode and RDE. The amount of $\mathrm{NO}_{x}$ emissions generated from these vehicle models was $0.009-0.075 \mathrm{~g} / \mathrm{km}$, which satisfactorily meets the standards for permissible emissions in certification 
tests. Therefore, it can be concluded that both LNT and SCR systems should be simultaneously applied in vehicles to satisfy both the standards for permissible emissions in certification tests and the standards for RDE.

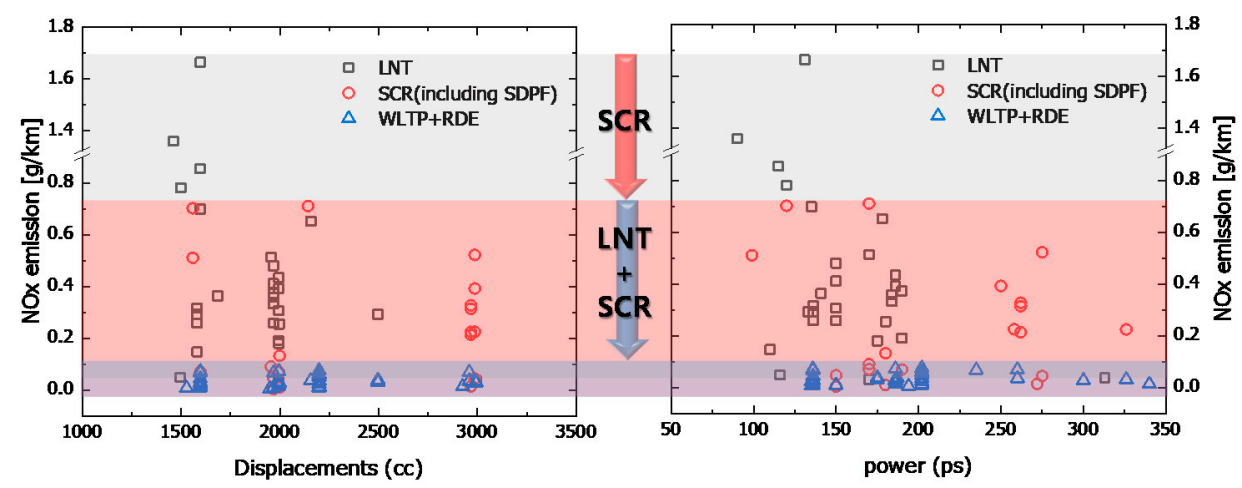

Figure 11. $\mathrm{NO}_{\mathrm{x}}$ emission characteristics on $\mathrm{RDE}$ test of light duty diesel vehicles with EURO-6 emission standard according to the after-treatment system.

\subsection{Emission Characteristics According to the After-Treatment System}

\subsubsection{Emission Characteristics by Chassis Dynamometer According to After-Treatment System}

Figure 12 shows the emission characteristics according to after-treatment systems, which were obtained from the vehicle models that comply with the Euro 6 standards under the conditions of NEDC and WLTP modes. The top panel of Figure 12a shows the amount of emissions measured in the NEDC mode. This figure shows the amount of $\mathrm{CO}, \mathrm{NO}_{x}$, and $\mathrm{HC}$ emissions was low, at $0.1 \mathrm{~g} / \mathrm{km}$ or less. Moreover, significant changes in patterns according to after-treatment systems were not observed. However, the amount of $\mathrm{NO}_{\mathrm{x}}$ emissions generated from vehicle models equipped with the LNT system increased rapidly in the WLTP mode. This result was obtained because the emission reduction performance of the LNT system decreased because of the larger number of acceleration and deceleration sections and greater maximum speed in the WLTP mode, compared with those in the NEDC mode. Since WLTP mode has harsher conditions than NEDC mode, it is reported that regeneration of after-treatment device such as LNT occurs more frequently and $\mathrm{NO}_{\mathbf{x}}$ emissions increase [20,21]. It was reported that tin this case the fuel economy of the vehicle would also deteriorate [22]. In contrast, the amount of $\mathrm{NO}_{\mathrm{x}}$ emissions generated from vehicle models equipped with the SCR system tended to be similar or decreased in the WLTP mode [19]. It was found that changes in the amount of CO and $\mathrm{HC}$ emissions according to after-treatment systems or driving modes were insignificant. The graphs in Figure $12 \mathrm{~b}$ indicate the tendency of the average amount of emissions generated from the two vehicle models according to after-treatment systems. It was found that the amount of emissions according to after-treatment systems was insignificant in the NEDC mode, and the application of both LNT and SCR systems in vehicle models resulted in better emission reduction performance. In the WLTP mode, the average amount of $\mathrm{NO}_{x}$ emissions from vehicle models equipped with the LNT system was high. Contrarily, the average amount of $\mathrm{NO}_{x}$ emissions from vehicle models equipped with the SCR system was low. This result indicates that the SCR system should be installed in vehicles to satisfy the WLTP standard, which is a reinforced test method. The amount of CO and HC emissions in the WLTP mode was found to be less than that in the NEDC mode, because it was affected by combustion activation due to increased temperature of exhaust gas caused by an increase in driving distance and the number of acceleration and deceleration sections. 


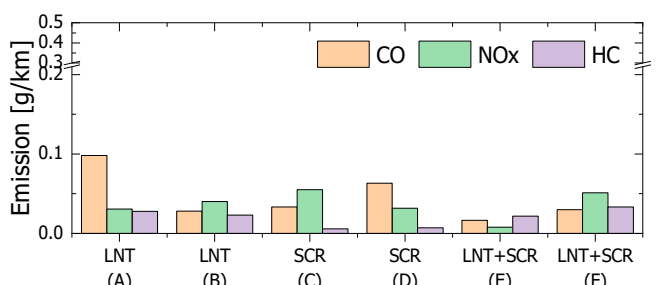

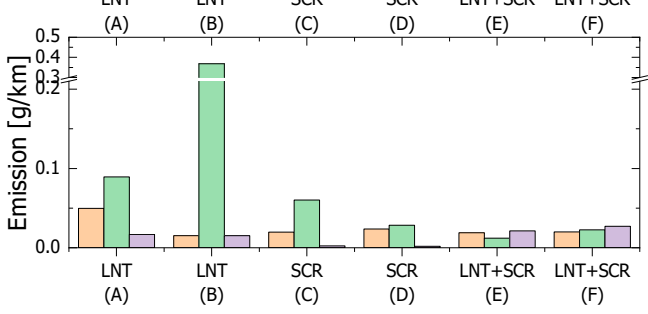

(a)
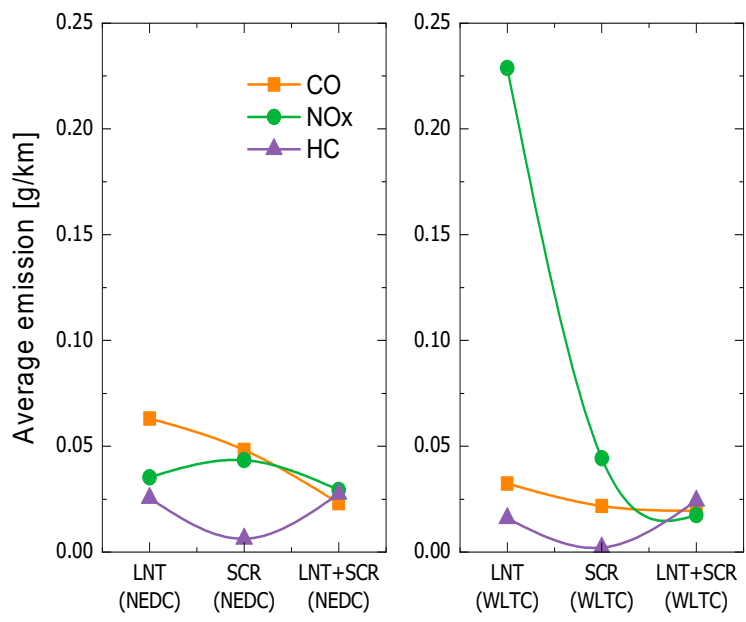

(b)

Figure 12. Emission characteristics of test vehicles in New European Driving Cycle (NEDC) and Worldwide Harmonized Light Vehicle Test Procedure (WLTP) modes according to the after-treatment system. (a) Measured emission values; (b) Average emission patterns.

Figure 13 shows the characteristics of PM emissions generated from test vehicle models in different driving modes according to the after-treatment systems. Based on the Euro 6 standards for permissible emissions, the amount of permissible PM emissions was set as $0.0045 \mathrm{~g} / \mathrm{km}$. It was found that the amount of PM emissions generated from test vehicle models was $0.001 \mathrm{~g} / \mathrm{km}$ or lower, which is lower than the permissible amount in the Euro 6 standards. This result was obtained because the DPF, which is a PM deduction system, was applied in all test vehicle models. Furthermore, a variation in tendency according to the test modes and after-treatment systems for $\mathrm{NO}_{\mathrm{x}}$ emissions was not found.

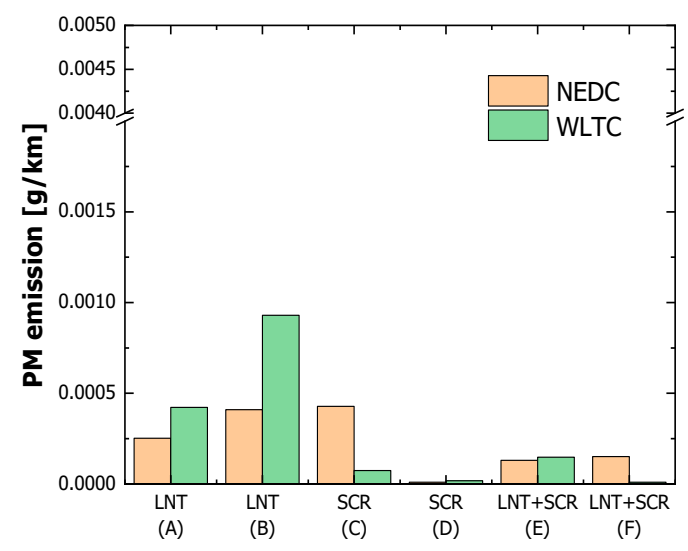

Figure 13. Particulate matter (PM) emission characteristics of test vehicles in the NEDC and WLTP modes according to the after-treatment system.

\subsubsection{Emission Characteristics by PEMS According to After-Treatment System}

To analyze the emission characteristics according to the after-treatment system during real road driving, in addition to those obtained through a certification test under the conditions of different driving modes, RDE tests on each group of two vehicle models according to the after-treatment systems were conducted under the conditions of cold- and hot-starting modes, respectively. The RDE tests were conducted in three sections, namely, urban, rural, and motorway routes, and the amount of $\mathrm{NO}_{\mathrm{x}}$ emissions among the gaseous contaminants was measured. Driving was performed on the routes in the order of urban, rural, and motorway routes, and the proportion of driving distance was maintained at 
$29 \%$ or higher in the urban route. An error of $\pm 10 \%$ was permitted during driving. The amount of $\mathrm{NO}_{\mathrm{x}}$ emissions was measured using the moving average window (MAW) method. Figure 14 shows the test results, with bar graphs representing the amount of $\mathrm{NO}_{\mathrm{x}}$ emissions according to the routes and dotted line graphs shown above the bar graphs representing the average amount of $\mathrm{NO}_{\mathrm{x}}$ emissions generated from the test vehicle models according to the after-treatment systems. These results indicate that the amount of $\mathrm{NO}_{x}$ emissions increased during hot-start driving, and increased significantly during driving on the urban route. This result was obtained because more regions with heavy traffic have an urban route in the hot-start condition compared with the urban route in the cold-start condition. Therefore, the exhaust temperature for the operation of after-treatment systems decreased due to the decreased vehicle speed and increased number of stop sections. It was also observed that vehicle models equipped with the LNT system generated greater amounts of $\mathrm{NO}_{\mathrm{x}}$ emissions than those with the SCR system or the combination of LNT and SCR systems. As indicated by the test results shown in Figure 14 obtained in the NEDC and WLTP modes, after-treatment systems exhibited limited performance during real road driving. In particular, their performance significantly decreased at the sections of deceleration and stoppage on the urban route in the hot-start condition. The LNT system requires a certain level of driving speed owing to its regeneration characteristics. Furthermore, $\mathrm{NO}_{\mathrm{x}}$ slip occurred as smooth regeneration was interrupted at the deceleration sections, thereby decreasing the performance of the LNT system. These results conclusively indicate that the SCR system should be installed in vehicles to satisfy the Euro 6 standards for permissible emissions for real road driving [21]. As indicated by the results of analysis of the average amount of $\mathrm{NO}_{\mathrm{x}}$ emissions, vehicle models equipped with the SCR system or the combination of LNT and SCR systems generated $\mathrm{NO}_{\mathrm{x}}$ emissions of $0.1 \mathrm{~g} / \mathrm{km}$ or less on average owing to the stable emission reduction performance of these systems. It was found that vehicle models equipped with the combination of LNT and SCR systems did not always exhibit a significantly improved performance in emission reduction, compared with those equipped only with the SCR system. This result was obtained because vehicle manufacturers set the operating area and emission reduction performance of LNT and SCR systems based on different emission control strategies.

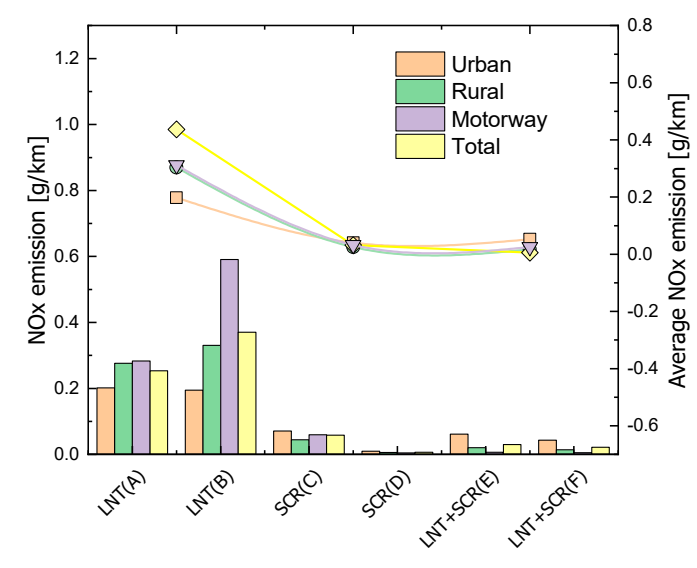

(a)

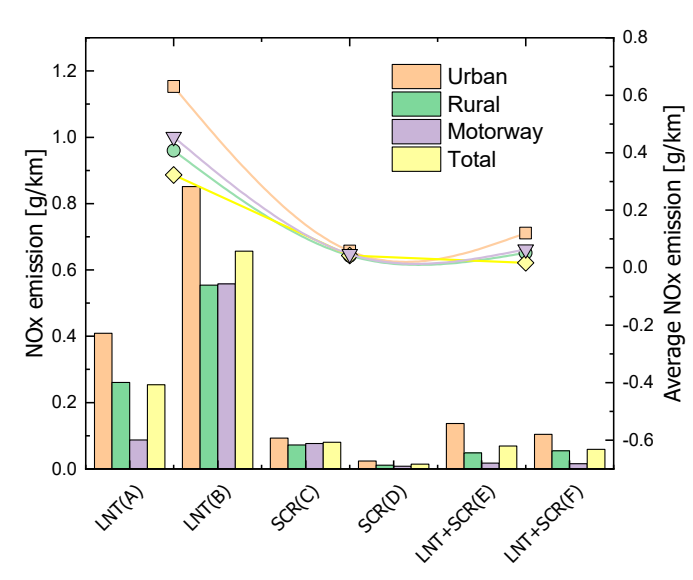

(b)

Figure 14. $\mathrm{NO}_{\mathrm{x}}$ emission characteristics of test vehicles in the RDE test according to after-treatment system. (a) Cold start; (b) Hot start.

\section{Conclusions}

This study examined the emission characteristics of diesel vehicles, which passed compliance tests and inspection on certification of conformity and complied with the Euro 6 standards, based on the power, displacement, and characteristics of $\mathrm{NO}_{\mathrm{x}}$ emissions according to the year of certification. Moreover, vehicles classified according to after-treatment systems were placed on a chassis dynamometer for the emission test. Further, an RDE test using the PEMS was conducted to 
identify the characteristics of emissions generated during real-road driving and compare the amount of emissions. The test results are as follows:

(1) The amount of $\mathrm{NO}_{\mathrm{x}}$ emissions has been decreasing since the implementation of RDE standards in 2017 and the advancements in after-treatment systems. It was found that the application of EGR and LNT systems tends to be limited to domestic and imported vehicle models with low displacement, and the SCR system is applied in all vehicle models regardless of displacement. It was also determined that the combination of LNT and SCR systems can be applied in vehicle models regardless of the power and displacement, and that it decreases the emissions.

(2) The results of analysis of the status of $\mathrm{NO}_{x}$ after-treatment systems installed in 266 vehicle models sold in Korea indicate that the SCR system accounts for $\sim 47 \%$ of all after-treatment systems installed in the test vehicle models, thus constituting the highest proportion. The number of vehicle models equipped with both LNT and SCR systems has been increasing since the implementation of standards for RDE in 2017. Moreover, the measurement results of the RDE of 83 vehicle models that comply with the Euro 6 standards, which were obtained through compliance tests and inspection on certification of conformity, were analyzed according to after-treatment systems. Based on the obtained results, it was verified that both LNT and SCR systems should be simultaneously applied in vehicles to satisfy the standards for permissible emissions for certification and the acceptable level of emissions generated during real road driving.

(3) The test results obtained according to the driving modes and after-treatment systems indicate that the amount of $\mathrm{CO}, \mathrm{NO}_{\mathrm{x}}$, and $\mathrm{HC}$ emissions generated in the NEDC driving mode was low, at $\leq 0.1 \mathrm{~g} / \mathrm{km}$. In addition, significant changes in patterns according to after-treatment systems were not observed. It was also found that the amount of $\mathrm{NO}_{\mathrm{x}}$ emissions generated from vehicles equipped with the SCR system displayed insignificant changes and tended to decrease.

(4) An analysis of $\mathrm{NO}_{x}$ emissions from real-road in Euro-6 light-duty diesel vehicle equipped with after-treatment devices operating in Korea showed that vehicles equipped with SCRs had lower emissions than those equipped with LNT. From these findings, it is believed that SCR fitment would be more advantageous to meet future emissions reduction of light-duty diesel vehicles on real-roads and enhanced emissions regulations above Euro-6.

Author Contributions: All authors contributed to the experiments, analysis, and the deployment of the paper. Conceptualization, Data curation, Investigation, Methodology, Writing-Original draft, H.J.K.; Data curation, Investigation, S.H.L., J.H.K., J.L.; Methodology, Resources, S.I.K., S.P. (Sangki Park); Funding acquisition, Resources, J.T.L.; Supervision, Writing-Review and Editing, S.P. (Suhan Park). All authors have read and agreed to the published version of the manuscript.

Funding: This work was funded by the National Institute of Environmental Research (NIER) (grant number NIER-2019-04-01-001), affiliated with the Ministry of the Environment of the Republic of Korea (Korean MOE).

Conflicts of Interest: The authors declare no conflict of interest. The funders had no role in the design of the study; in the collection, analyses, or interpretation of data; in the writing of the manuscript, or in the decision to publish the results.

\section{References}

1. Statistical Data of the Ministry of Land, Infrastructure and Transport, Korea. Available online: http: //stat.molit.go.kr (accessed on 18 September 2020).

2. The Clean Air Conservation Act Enforcement Rules. No.17326. 2020.

3. Degraeuwe, B.; Weiss, M. Does the New European Driving Cycle (NEDC) really fail to capture the $\mathrm{NO}_{\mathrm{x}}$ emissions of diesel cars in Europe? Environ. Pollut. 2017, 222, 234-241. [CrossRef] [PubMed]

4. Sileghem, L.; Bosteels, D.; May, J.; Favre, C.; Verhelst, S. Analysis of vehicle emission measurements on the new WLTC, the NEDC and the CADC. Transp. Res. Part D 2014, 32, 70-85. [CrossRef]

5. Ko, S.; Park, J.; Kim, H.; Kang, G.; Lee, J.; Kim, J.; Lee, J. NOx Emissions from Euro 5 and Euro 6 Heavy-Duty Diesel Vehicles under Real Driving Conditions. Energies 2020, 13, 218. [CrossRef] 
6. Gallus, J.; Kirchner, U.; Vogt, R.; Benter, T. Impact of driving style and road grade on gaseous exhaust emissions of passenger vehicles measured by a Portable Emission Measurement System (PEMS). Transp. Res. Part D 2017, 52, 215-226. [CrossRef]

7. Li, F.; Zhuang, J.; Cheng, X.; Li, M.; Wang, J.; Yan, Z. Investigation and prediction of heavy-duty diesel passenger bus emissions in Hainan using a COPERT model. Atmosphere 2019, 10, 106. [CrossRef]

8. Mahesh, S.; Ramadurai, G.; Nagendra, S. Real-world emissions of gaseous pollutants from diesel passenger cars using portable emission measurement systems. Sustain. Cities Soc. 2018, 41, 104-113. [CrossRef]

9. Lee, T.; Park, J.; Kwon, S.; Lee, J.; Kim, J. Variability in operation-based NOx emission factors with different test routes, and its effects on the real-driving emissions of light diesel vehicles. Sci. Total Environ. 2013, 461, 377-385. [CrossRef] [PubMed]

10. Keramydas, C.; Papadopoulos, G.; Ntziachristos, L.; Lo, T.-S.; Ng, K.-L.; Wong, H.-L.A.; Wong, C.K.-L. Real-World Measurement of Hybrid Buses' Fuel Consumption and Pollutant Emissions in a Metropolitan Urban Road Network. Energies 2018, 11, 2569. [CrossRef]

11. O'Driscoll, R.; Stettler, M.E.J.; Molden, N.; Oxley, T.; Apsimon, H.M. Real world $\mathrm{CO}_{2}$ and $\mathrm{NO}_{\mathrm{x}}$ emissions from 149 Euro 5 and 6 diesel, gasoline and hybrid passenger cars. Sci. Total Environ. 2018, 621, 282-290. [CrossRef] [PubMed]

12. Huang, C.; Lou, D.; Hua, Z.; Feng, Q.; Chen, Y.; Chen, C.; Tan, P.; Yao, D. A PEMS study of the emissions of gaseous pollutants and ultrafine particles from gasoline- and diesel-fueled vehicles. Atmos. Environ. 2013, 77, 703-710. [CrossRef]

13. Mera, Z.; Fonseca, N.; Lopez, J.; Casanova, J. Analysis of the high instantaneous NOx emissions from Euro 6 diesel passenger cars under real driving conditions. Appl. Energy 2019, 272, 1074-1089. [CrossRef]

14. Ko, J.; Myung, C.L.; Park, S. Impacts of ambient temperature, DPF regeneration, and traffic congestion on NOx emissions from a Euro 6-compliant diesel vehicle equipped with an LNT under real-world driving conditions. Atmos. Environ. 2019, 200, 1-14. [CrossRef]

15. Hernandez, J.J.; Rodriguez-Fernandez, J.; Calle-Asensio, A. Performance and regulated gaseous emissions of a Euro 6 diesel vehicle with Lean NOx Trap at different ambient conditions: Sensitivity to the type of fuel. Energy Convers. Manag. 2020, 219, 113023. [CrossRef]

16. Myung, C.; Jang, W.; Kwon, S.; Ko, J.; Jin, D.; Park, S. Evaluation of the real-time de-NOx performance characteristics of a LNT-equipped Euro 6 diesel passenger car with various vehicle emissions certification cycles. Energy 2017, 132, 356-369. [CrossRef]

17. Lujan, J.M.; Bermudez, V.; Dolz, V.; Monsalve-Serrano, J. An assessment of the real-world driving gaseous emissions from a Euro 6 light-duty diesel vehicle using a portable emissions measurement system (PEMS). Atmos. Environ. 2018, 174, 112-121. [CrossRef]

18. Chong, H.S.; Park, Y.; Kwon, S.; Hong, Y. Analysis of real driving gaseous emissions from light-duty diesel vehicles. Transp. Res. Part D 2018, 65, 485-499. [CrossRef]

19. Cha, J.; Lee, J.; Chon, M.S. Evaluation of real driving emissions for Euro 6 light-duty diesel vehicles equipped with LNT and SCR on domestic sales in Korea. Atmos. Environ. 2019, 196, 133-142. [CrossRef]

20. Triantafyllopoulos, G.; Dimaratos, A.; Ntziachristos, L.; Bernard, Y.; Dornoff, J.; Samaras, Z. A study on the $\mathrm{CO}_{2}$ and $\mathrm{NO}_{\mathrm{x}}$ emissions performance of Euro 6 diesel vehicles under various chassis dynamometer and on-road conditions including latest regulatory provisions. Sci. Total Environ. 2019, 666, 337-346. [CrossRef] [PubMed]

21. Ko, J.; Jin, D.; Jang, W.; Myung, C.; Kwon, S.; Park, S. Comparative investigation of NOx emission characteristics from a Euro 6-compliant diesel passenger car over the NEDC and WLTC at various ambient temperatures. Appl. Energy 2017, 187, 652-662. [CrossRef]

22. Lee, H.; Lee, K. Comparative Evaluation of the Effect of Vehicle Parameters on Fuel Consumption under NEDC and WLTP. Energies 2020, 13, 4245. [CrossRef]

(C) 2020 by the authors. Licensee MDPI, Basel, Switzerland. This article is an open access article distributed under the terms and conditions of the Creative Commons Attribution (CC BY) license (http://creativecommons.org/licenses/by/4.0/). 